\title{
EQUAL SACRIFICE AND FAIR BURDEN SHARING IN A PUBLIC GOODS ECONOMY
}

\author{
WOLFGANG BUCHHOLZ \\ WOLFGANG PETERS
}

CESIFO WORKING PAPER NO. 1997

CATEGORY 8: RESOURCES AND ENVIRONMENT

MAY 2007

An electronic version of the paper may be downloaded

- from the SSRN website:

- from the RePEc website:

www.SSRN.com

- from the CESifo website:

www.RePEc.org

www.CESifo-group.de 


\title{
EQUAL SACRIFICE AND FAIR BURDEN SHARING IN A PUBLIC GOODS ECONOMY
}

\begin{abstract}
Applying a willingness to pay approach known from contingent valuation in environmental economics, we develop an ordinally based measure for the size of individual sacrifice that is connected with an agent's contribution to a public good. We construct a selection mechanism that picks the unique efficient solution among all allocations that have an equal sacrifice as defined in this way. We show that the solution thus obtained correspond to Moulin's egalitarian equivalent allocation, conforms to both the ability to pay and the benefit principles, and has much in common with the Lindahl equilibrium.

JEL Code: H41.
\end{abstract}

Keywords: public goods, cooperative solutions, fairness, egalitarian equivalent solutions.

\author{
Wolfgang Buchholz \\ University of Regensburg \\ 93040 Regensburg \\ Germany \\ wolfgang.buchholz@wiwi.uni- \\ regensburg.de
}

\author{
Wolfgang Peters \\ European University Viadrina \\ PO Box 1786 \\ 15207 Frankfurt (Oder) \\ Germany \\ Peters@euv-frankfurt-o.de
}

May 22, 2007 


\section{Introduction}

Since the theory of public finance began in the $19^{\text {th }}$ century, three famous principles of just taxation based on different normative ideas have been formulated (see, e.g., Musgrave, 1959, for a historical review). The equal sacrifice principle requires that taxation should lead to the same (absolute or relative) loss of utility for everyone. In this way, a symmetrical, and thus fair, treatment of all citizens is ensured. Taxation according to ability to pay, on the other hand, requires that personal tax liability should be positively correlated with the taxpayer's income or wealth and thus provides some kind of vertical equity for people with different financial capacities. In contrast to both equal sacrifice and ability-to-pay, the benefit principle also takes into account how the tax revenue is spent. It postulates that the individual tax burden should be related to the utility gain an agent derives from the governmental expenditures that are financed with her taxes. The benefit principle therefore reflects the quid pro quo fairness known from the market exchange of private goods.

During the last couple of years, these basic concepts of just taxation have been attracting more attention in a field outside the framework of taxation theory in the ordinary sense. So it has become a major topic in the political debate and in economic research how to improve the supply of "global public goods". Climate protection has now become the most prominent of these goods (see, e.g., Kaul, Grunberg and Stern, 1999, Kaul et al., 2003, Sandler, 2004, Nordhaus, 2005, Sandmo, 2006, and Kaul and Conceição, 2006). Provision of a public good, however, is inefficiently low when agents (or, in the case of an international public good, countries) do not cooperate, such that collective actions are required to overcome this underprovision problem (see, e.g., Sandler, 1992, or Cornes and Sandler, 1996, for a detailed explanation of this standard result in the theory of public goods).

In the international sphere cooperation often is, as in the case of the Kyoto protocol in climate policy, regulated by a convention which, in particular, stipulates how the contributions to the global public good are to be distributed among the participating countries (especially with climate protection see Stern, 2006, pp. 450-467). The venerable principles of just taxation become relevant once again for designing the fundamental structure of such burden sharing arrangements: Countries will only be ready to accept an agreement when their advantage is in line with their financial obligations, i.e. if the benefit principle is satisfied. At the same time, cooperation can only be expected to be successful if no nation feels overburdened compared to its partners, and a fair distribution of cooperative efforts is achieved (see Sandler, 2004, pp. 77-79). This concern for an equitable treatment of all participants is reflected by the equal sacrifice principle. In the field of climate change policy there is, moreover, a broad con- 
sensus that richer countries have a greater obligation to finance greenhouse gas abatement, and this could be considered to be an application of the ability-to-pay principle.

Despite their importance, and their casual perception in the literature, the principles of just taxation as guidelines for fair burden sharing have not been incorporated systematically into the theory of public goods. The purpose of this paper is therefore to identify an approach where one particular efficient public good allocation that conforms simultaneously to these three principles is selected. Taking the equal sacrifice postulate as the starting point, we proceed as follows: In Section 2, we first describe how the individual sacrifice connected with a certain individual public good contribution can be measured by adopting a willingness-to-pay technique familiar in environmental economics. (For another application of the willingness to pay approach to the standard public good model see Bergstrom, 2006.) With this approach, individual contributions to the public good that were originally measured in units of the private good are converted into public-goods equivalents so that the public good serves as the numéraire. Thus, in contrast to the classical equal sacrifice approach in the theory of taxation, a cardinal measure for individual utility is not required. In Section 3, we first establish some basic properties of this sacrifice measure that are used throughout the paper. In Section 4, the equity norm is then applied to determine the set of public good allocations for which the level of this sacrifice is identical for all agents. Imposing allocative efficiency for the public good allocation, i.e. the Samuelson rule, as a further normative postulate then gives the desired choice mechanism for public-good allocations. In Section 5, it is shown that this mechanism corresponds to Moulin's egalitarian-equivalent solution concept (see Moulin, 1987, 1995). Thus an alternative justification for this selection mechanism is provided that is more closely related to standard ideas of equal treatment and to the standard concepts of public finance. In this way, it also becomes possible to draw a parallel between the egalitarian equivalent solution in a public goods economy and the classical Lindahl equilibrium which is also done in Section 5. In Section 6, we finally show that the equal sacrifice selection rule described in this paper also satisfies the benefit principle and the ability-to-pay criterion, so that it, indeed, incorporates the three fundamental principles for fair burden sharing. (An empirical account of concepts for fair burden sharing in international environmental agreements is given by Lange, Vogt and Ziegler, 2007.)

\section{Measuring Individual Sacrifice of Public Good Contribution}

We consider a standard public-good economy consisting of $n$ agents $i=1, \ldots, n$ (see the classical treatments in Bergstrom, Blume and Varian, 1986, and Cornes and Sandler, 1996). Agent $i$ 
is endowed with an amount $y_{i}$ of the private good, her income. Total income of all agents is denoted by $Y=\sum_{i=1}^{n} y_{i}$. The utility function of agent $i$ is $u_{i}\left(x_{i}, G\right)$ where $x_{i}$ is agent $i$ 's level of private consumption and $G$ is public-good supply. Each utility function is at least twice continuously differentiable and strictly monotone increasing in both variables, it is strictly quasiconcave and both the private and the public good are assumed to be non-inferior. To avoid corner solutions we furthermore suppose that in a $x_{i}-G$-diagram the indifference curves of all agents are tangential to the coordinate axis as, e.g., in the Cobb-Douglas case. Given the utility function $u_{i}\left(x_{i}, G\right)$ the marginal rate of substitution between the public good and the private good at some point $\left(x_{i}, G\right)$ is denoted by $\pi_{i}\left(x_{i}, G\right)=\frac{\partial u_{i} / \partial G}{\partial u_{i} / \partial x_{i}}$.

The public good is produced by a constant returns to scale summation technology. If agent $i$ contributes $g_{i}:=y_{i}-x_{i}$ to the public good, the total supply of the public good is given by

$$
G=\sum_{i=1}^{n} g_{i}
$$

Among all allocations that meet the budget constraint (1), we want to identify those in which the sacrifice for each agent is equal and thus the equal sacrifice principle is satisfied. Applying this normative concept first of all requires the size of personal sacrifice to be measured in an adequate way. In this context, the simplest approach would be to identify agent i's sacrifice with the absolute level of her contribution $g_{i}$. But such a specification of sacrifice is only compatible with ethical intuition when all agents are completely identical, i.e. have the same income and the same preferences. Otherwise, one would expect a smaller income, or a lower preference for the public good, to increase agent $i$ 's subjective burden associated with some given contribution level $g_{i}$, since this contribution then is harder for her to bear.

The problem of finding an adequate measure of subjective individual sacrifice already showed up in the classical treatment of equal sacrifice of taxation where sacrifice was related to the loss of utility of income and not to income itself. In this approach utility has to be cardinally measurable, which is in conflict with the usual assumption of purely ordinal preferences. (For a modern treatment of the classical equal sacrifice approach see, e.g., Mitra and Ok, 1996, or Moyes, 2003). In the present paper, in which the agents' utility also depends on public good consumption, a measure of agent i's personal sacrifice is obtained by construct- 
ing a public-good equivalent to her contribution $g_{i}$. As we take the public good as a numéraire, the problem of having to make use of cardinal measurability of utility that was pertinent in the classical equal sacrifice approach is avoided. ${ }^{1}$

Definition 1: Let $A=\left(\tilde{x}_{1}, \ldots, \tilde{X}_{n}, \tilde{G}\right)$ be some allocation that is feasible according to (1). The individual sacrifice $s_{i}^{M}(A)$ that agent $i$ makes in the allocation $A$ is determined by

$$
u_{i}\left(y_{i}, \tilde{G}-s_{i}^{M}(A)\right)=u_{i}\left(\tilde{x}_{i}, \tilde{G}\right)
$$

The meaning of Definition 1 is visualised in Figure 1.

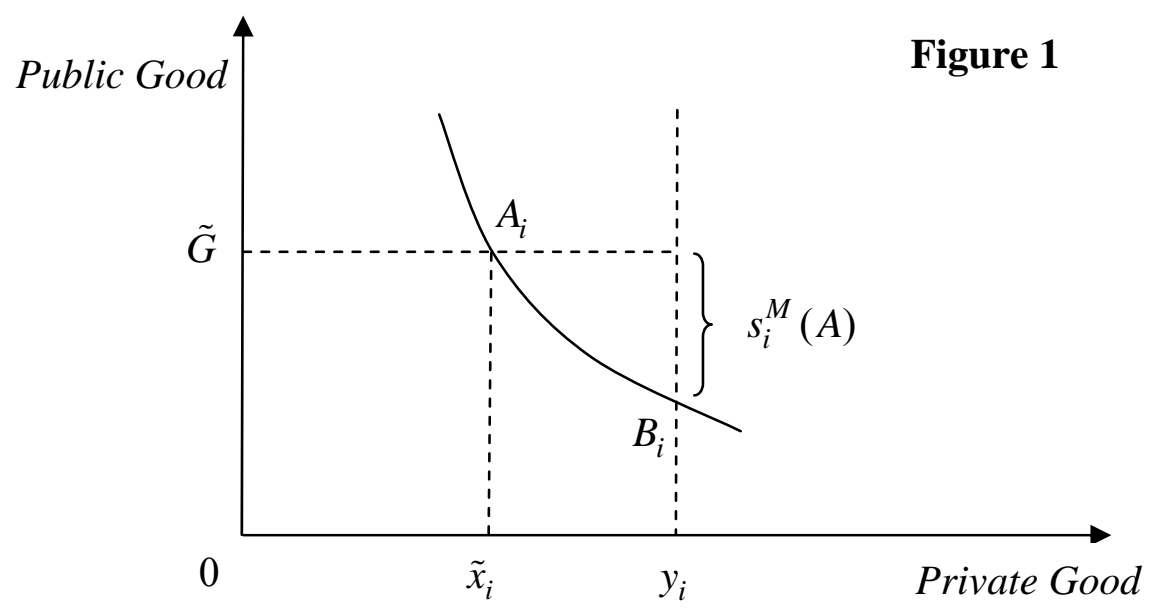

By Definition 1, individual public-good contributions $g_{i}$ are converted into equivalent publicgood units and thus made comparable. This method for measuring the personal sacrifice is analogous to the assessment of individual willingness to pay well-known from contingent valuation studies in environmental economics (see e.g. Ebert, 1993, or Kolstad, 2000, pp. 291-294). So, agent $i$ 's sacrifice $s_{i}^{M}(A)$ in a given allocation $A=\left(\tilde{X}_{1}, \ldots \tilde{X}_{n}, \tilde{G}\right)$ is elicited as the answer to a willingness-to-pay question by which agent $i$ is asked how much of the public good she would be ready to give up if - starting from her position $\left(\tilde{X}_{i}, \tilde{G}\right)$ - she could simultaneously reduce her public-good contribution to zero. Then agent $i$ becomes indifferent between her position $A_{i}=\left(\tilde{x}_{i}, \tilde{G}\right)$ attained in $A$ and the position $B_{i}=\left(y_{i}, \tilde{G}-s_{i}^{M}(A)\right)$ where pri-

\footnotetext{
${ }^{1}$ See Neill (2000) for an alternative approach to measuring individual sacrifice in a public-goods economy that, as in the conventional treatments, refers to differences in cardinal utility.
} 
vate consumption is identical with the initially given income $y_{i}$ and the public-good supply is reduced by the sacrifice level $s_{i}^{M}(A)$. In an alternative interpretation, $s_{i}^{M}(A)$ indicates agent i's willingness to pay (in units of the public good) for an increase of private consumption from $\tilde{x}_{i}$ to $y_{i}$.

Let - for any utility level $\bar{u}_{i}$ of agent $i-\varphi_{i}^{h}\left(x_{i}, \bar{u}_{i}\right)$ denote the inverse Hicksian demand function for the private good which coincides with the marginal rate of substitution between the private good and the public good $1 / \pi_{i}\left(x_{i}, G\right)$ when $\left(x_{i}, G\right)$ varies along the given indifference curve which we will identify with the utility level $\bar{u}_{i}$ throughout the paper. Then $s_{i}^{M}(A)$ can be represented as an area below the inverse Hicksian demand function, i.e. as

$$
s_{i}^{M}(A)=\int_{x_{i}}^{y_{i}} \varphi_{i}^{h}\left(x_{i}, u_{i}\left(\tilde{x}_{i}, \tilde{G}\right)\right) d x_{i}=\tilde{g}_{i} \int_{x_{i}}^{y_{i}} \frac{\varphi_{i}^{h}\left(x_{i}, u_{i}\left(\tilde{x}_{i}, \tilde{G}\right)\right)}{\tilde{g}_{i}} d x_{i},
$$

where $\tilde{g}_{i}:=y_{i}-\tilde{x}_{i}$ is agent $i$ 's public-good contribution in the allocation $A$. Thus the sacrifice of agent $i$ in allocation $A$ is obtained as this agent's contribution to the public good, weighted by the average marginal rate of substitution measured along the indifference curve $u_{i}\left(\tilde{x}_{i}, \tilde{G}\right)$.

\section{Properties of the Sacrifice Measure}

In this section we want to examine how the level of agent $i$ 's sacrifice depends on her position $\left(\tilde{x}_{i}, \tilde{G}\right)=\left(y_{i}-\tilde{g}_{i}, \tilde{G}\right)$ attained in a certain allocation $A$ and also on her income $y_{i}$ and her preferences $u_{i}\left(x_{i}, G\right)$. In the following four steps of the analysis, we will vary only one of the parameters $\tilde{g}_{i}, \tilde{G}$ and $y_{i}$ or the utility function $u_{i}\left(x_{i}, G\right)$, while the other three are kept constant. Part of the adjustment that is required by the transition from the original allocation $A$ to a new feasible allocation called $A^{\prime}$ then has to be made by the other agents. The change of agent $i$ 's sacrifice, however, is not affected by the precise nature of the adjustments of the other agents so that they do not have to be described explicitly.

(i) If agent $i$ 's public good contribution is increased from $\tilde{g}_{i}$ to $\tilde{g}_{i}^{\prime}$, her sacrifice obviously increases, since the new indifference curve $u_{i}\left(\tilde{x}_{i}^{\prime}, \tilde{G}\right)$ is lower than the original indifference curve $u_{i}\left(\tilde{x}_{i}, \tilde{G}\right)$. 
(ii) If public-good supply grows from $\tilde{G}$ to $\tilde{G}^{\prime}$, the argument is a little more complicated and crucially depends on the normality assumption. Letting $\tilde{u}_{i}:=u_{i}\left(\tilde{x}_{i}, \tilde{G}\right)$ and $\tilde{u}_{i}^{\prime}:=u_{i}\left(\tilde{x}_{i}, \tilde{G}^{\prime}\right)$ we consider the two inverse Hicksian demand functions $\varphi_{i}^{h}\left(x_{i}, \tilde{u}_{i}\right)$ and $\varphi_{i}^{h}\left(x_{i}, \tilde{u}_{i}^{\prime}\right)$ that correspond to these utility levels, respectively. From $\tilde{G}^{\prime}>\tilde{G}$, we have $\tilde{u}_{i}^{\prime}>\tilde{u}_{i}$, Then normality straightforwardly implies that $\varphi_{i}^{h}\left(x_{i}, \tilde{u}_{i}^{\prime}\right) \geq \varphi_{i}^{h}\left(x_{i}, \tilde{u}_{i}\right)$ holds for all $x_{i}$, so that the indifference curve through $\left(\tilde{x}_{i}, \tilde{G}^{\prime}\right)$ is, for any $x_{i}$, steeper than that through $\left(\tilde{x}_{i}, \tilde{G}\right)$ (see Appendix A1 for details). Using our representation formula (3), this allows a comparison of the new sacrifice $s_{i}^{M}\left(A^{\prime}\right)$ (with the new position $\left(\tilde{x}_{i}, \tilde{G}^{\prime}\right)$ of agent $i$ ) and the original sacrifice level $s_{i}^{M}(A)$

$$
s_{i}^{M}\left(A^{\prime}\right)=\int_{\tilde{x}_{i}}^{y_{i}} \varphi_{i}^{h}\left(x_{i}, \tilde{u}_{i}^{\prime}\right) d x_{i} \geq \int_{\tilde{x}_{i}}^{y_{i}} \varphi_{i}^{h}\left(x_{i}, \tilde{u}_{i}\right) d x_{i}=s_{i}^{M}(A) .
$$

(iii) If the income of agent $i$ is increased from $y_{i}$ to $y_{i}^{\prime}$ the effect on the sacrifice level again rests upon normality. Letting now $\tilde{u}_{i}^{\prime}:=u_{i}\left(y_{i}^{\prime}-\tilde{g}_{i}, \tilde{G}\right)$, we consider the inverse Hicksian demand function $\varphi_{i}^{h}\left(x_{i}, \tilde{u}_{i}^{\prime}\right)$. If a horizontal translation by $t:=y_{i}^{\prime}-y_{i}$ is made, normality implies $\varphi_{i}^{h}\left(x_{i}, \tilde{u}_{i}^{\prime}\right) \leq \varphi_{i}^{h}\left(x_{i}-t, \tilde{u}_{i}\right)$, i.e. moving to the right makes the indifference curves flatter (see again Appendix A1). Denoting $\tilde{x}_{i}^{\prime}=y_{i}^{\prime}-\tilde{g}_{i}$, we then get the following estimate:

$$
s_{i}^{M}\left(A^{\prime}\right)=\int_{\tilde{x}_{i}^{\prime}}^{y_{i}^{\prime}} \varphi_{i}^{h}\left(x_{i}, \tilde{u}_{i}^{\prime}\right) d x_{i} \leq \int_{\tilde{x}_{i}^{\prime}}^{y_{i}^{\prime}} \varphi_{i}^{h}\left(x_{i}-t, \tilde{u}_{i}\right) d x_{i}=\int_{\tilde{x}_{i}}^{y_{i}} \varphi_{i}^{h}\left(x_{i}, \tilde{u}_{i}\right) d x_{i}=s_{i}^{M}(A) .
$$

This means that agent $i$ 's sacrifice becomes smaller if her income increases.

(iv) Finally, we suppose that agent $i$ is substituted by another type of agent with a utility function $u_{i}^{\prime}\left(x_{i}, G\right)$ which represents a weaker preference for the public good than the original utility function $u_{i}\left(x_{i}, G\right)$. This intensification of preferences for the public good is described by the assumption that the new utility function everywhere exhibits a higher marginal willingness to pay for the public good, i.e. that 


$$
\frac{\partial u_{i}^{\prime} / \partial G}{\partial u_{i}^{\prime} / \partial x_{i}}>\frac{\partial u_{i} / \partial G}{\partial u_{i} / \partial x_{i}}
$$

holds for all consumption bundles $\left(x_{i}, G\right)$. This condition means that the indifference curve $\tilde{u}_{i}^{\prime}:=u_{i}^{\prime}\left(\tilde{x}_{i}, \tilde{G}\right)$ is flatter in the point $\left(\tilde{x}_{i}, \tilde{G}\right)$ than the original indifference curve $\tilde{u}_{i}=u_{i}\left(\tilde{x}_{i}, \tilde{G}\right)$. The two indifference curves $\tilde{u}_{i}$ and $\tilde{u}_{i}^{\prime}$ cannot cross twice because this would violate assumption (6). So, the indifference curve $\tilde{u}_{i}^{\prime}$ must lie above the indifference curve $\tilde{u}_{i}$ right to $\tilde{x}_{i}$ which clearly implies that agent $i$ 's sacrifice is reduced.

We summarize these findings as follows:

Proposition 1: The individual sacrifice of an agent becomes higher if

(i) the public-good contribution, or

(ii) total public-good supply increases.

The individual sacrifice of an agent is lower if

(iii) her income increases, or

(iv) her preferences for the public good become stronger.

\section{Equal Sacrifice Allocations}

Having developed a concept for the measurement of sacrifice it is now straightforward to characterize equal sacrifice allocations. This is made precise by the next definition.

Definition 2: Let an income distribution $\left(y_{1}, \ldots, y_{n}\right)$ and preferences $\left(u_{1}, \ldots, u_{n}\right)$ be given. A feasible allocation $A=\left(\tilde{x}_{1}, \ldots, \tilde{x}_{n}, \tilde{G}\right)$ is called an equal sacrifice allocation when there is some sacrifice level $s>0$ such that

$$
s_{i}^{M}(A)=s \quad \text { for all } i=1, \ldots, n .
$$

In order to show that such equal sacrifice solutions exist, we use the following construction in which we start with some public good level $G \in] 0, Y]$. We then define for any sacrifice level $s \in\left[0, G\left[\right.\right.$ a private consumption level $\breve{x}_{i}(s, G)$ of agent $i$ by letting 


$$
u_{i}\left(\breve{x}_{i}(s, G), G\right)=u_{i}\left(y_{i}, G-s\right) .
$$

Thus, as depicted in Figure 2, $\breve{x}_{i}(s, G)$ is agent $i$ 's private consumption level when publicgood supply is $G$ and this agent should bear the given sacrifice $s$.

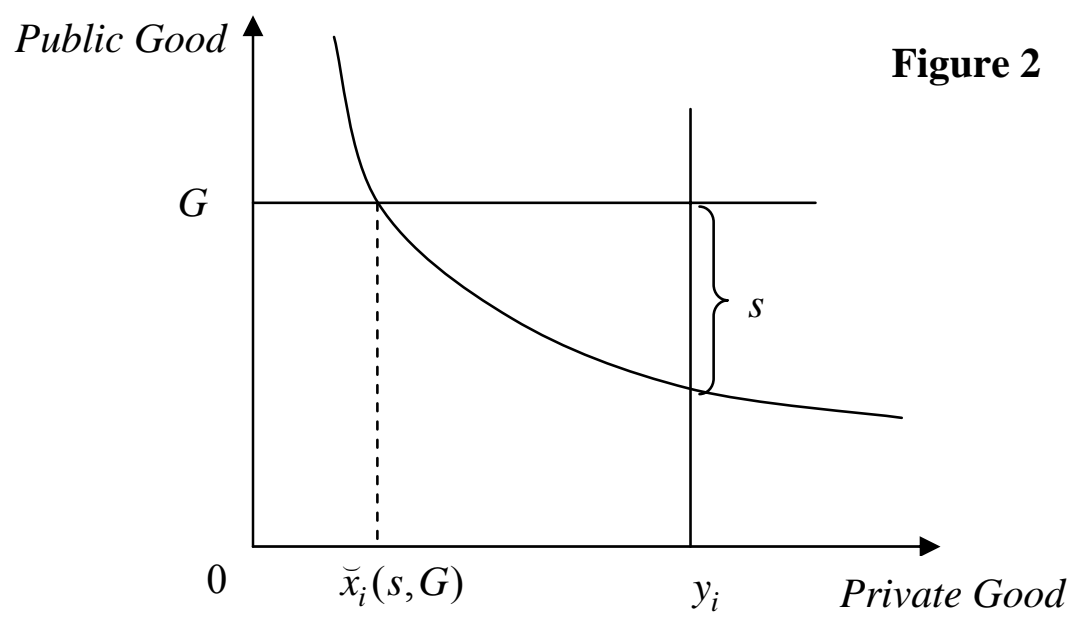

Given our assumption that all indifference curves are tangential to the $G$ axis, a unique private-good consumption level $\breve{x}_{i}(s, G)$ exists for all $\left.\left.G \in\right] 0, Y\right]$ and all $s \in[0, G[$. Obviously, $\breve{x}_{i}(s, G)$ is strictly decreasing in $s$ for a given public-good level $G$ and $\lim _{s \rightarrow G} \breve{X}_{i}(s, G)=0$ holds for any agent $i=1, \ldots, n$. Moreover, for a fixed sacrifice level $s, \breve{x}_{i}(s, G)$ is increasing in $G$, since it follows from parts (i) and (ii) of Proposition 1 that otherwise the sacrifice level would increase.

Having established these properties of the function $\breve{x}_{i}(s, G)$ we now consider the function

$$
H(s, G):=\sum_{i=1}^{n} \breve{x}_{i}(s, G)+G
$$

The function $H(s, G)$ defined by (8) describes how much aggregate income would be required if public-good supply were $G$ and all agents $i=1, \ldots, n$ had the equal sacrifice level $s$. The function $H(s, G)$ is differentiable in both variables and strictly decreasing in $s$, and from 
the properties of the functions $\breve{x}_{i}(s, G)$, it follows that $H(0, G)=Y+G>Y$ and $\lim _{s \rightarrow G} H(s, G)=G<Y$. Thus, by continuity and monotonicity of $H(s, G)$ in $G$, the mean-value theorem implies, that there is a unique value of sacrifice $s^{M}(G)$ such that

$$
H\left(s^{M}(G), G\right)=Y
$$

Hence, there exists a unique equal sacrifice allocation $\left(\breve{x}_{1}\left(s^{M}(G), G\right), \ldots, \breve{x}_{n}\left(s^{M}(G), G\right), G\right)$ that fulfils the budget constraint (1) with the public good supply $G$.

By equation (10), the function $s^{M}(G)$ is implicitly defined for all public good levels in ] $0, Y\left[\right.$, and, since $\lim _{G \rightarrow 0} s^{M}(G)=0$ and $\lim _{G \rightarrow Y} s^{M}(G)=Y$, this function takes on any value in this interval. Furthermore, from totally differentiating equation (9) we obtain

$$
\frac{\partial s^{M}(G)}{\partial G}=-\frac{\partial H / \partial G}{\partial H / \partial s}>0
$$

This inequality follows from $\partial H / \partial s<0$ and $\partial H / \partial G>0$, which holds, since each $\breve{x}_{i}(s, G)$ is decreasing in $s$ and increasing in $G$. As the function $s^{M}(G)$ is thus strictly increasing, it can be inverted. The inverse function of $s^{M}(G)$, which is called $G^{M}(s)$, then is defined on $] 0, Y[$ and it is strictly increasing, too. This yields the following result.

Proposition 2: For each $s \in] 0, Y$ [ there is a unique feasible allocation in which all agents have the equal individual sacrifice $s$.

Proof: Given $s$, let public-good supply be $G^{M}(s)$ and private consumption of agent $i$ be $x_{i}^{M}(s):=\breve{x}_{i}\left(s, G^{M}(s)\right)$. Then, by the construction above, $\left(x_{1}^{M}(s), \ldots, x_{n}^{M}(s), G^{M}(s)\right)$ is a feasible allocation in which all agents have the same sacrifice level $s$. As $G^{M}(s)$ is a strictly increasing function, the sacrifice level must be different from $s$ in any other feasible equal sacrifice allocation which shows uniqueness.

QED. 


\section{The Choice Mechanism}

Through Proposition 1 it becomes clear that there are infinitely many equal sacrifice solutions that could, depending on the sacrifice level $s$, be described by an "equal-sacrifice curve" $\left(x_{1}^{M}(s), \ldots, x_{n}^{M}(s), G^{M}(s)\right)$ in the $\square^{n+1}$-space. (See, e.g., Schlesinger and Sullivan, 1986, for a similar construction in the Kolm-triangle for the two-person case.) We now want to show that on this curve there is one single point that gives a Pareto-optimal allocation.

For a proof, consider the marginal rates of substitution between the public good and the private good along the equal sacrifice curve, i.e. we denote $\pi_{i}^{M}(s):=\pi_{i}\left(x_{i}^{M}(s), G^{M}(s)\right)$ for each agent $i=1, \ldots, n$ and each sacrifice level $s \in] 0, Y[$. From the supposed tangency properties of the indifference curves of all agents, we have $\lim _{s \rightarrow Y} \pi_{i}^{M}(s)=0$ as $\lim _{s \rightarrow Y} x_{i}^{M}(s)=0$ for all agents $i=1, \ldots, n$. In order to apply the Samuelson rule, we now denote $\Pi^{M}(s):=\sum_{i=1}^{n} \pi_{i}^{M}(s)$ as the sum of these marginal rates of substitution. Clearly, $\lim _{s \rightarrow Y} \prod^{M}(s)=0$ and $\lim _{s \rightarrow 0} \prod^{M}(s)=\infty$ so that there is some $\left.s^{*} \in\right] 0, Y\left[\right.$ for which $\Pi^{M}\left(s^{*}\right)=1$. The feasible equal sacrifice allocation $\left(x_{1}^{M}\left(s^{*}\right), \ldots, x_{n}^{M}\left(s^{*}\right), G^{M}\left(s^{*}\right)\right)$ then fulfils the Samuelson condition and thus is Pareto-optimal.

In order to show that $\left(x_{1}^{M}\left(s^{*}\right), \ldots, x_{n}^{M}\left(s^{*}\right), G^{M}\left(s^{*}\right)\right)$ is the unique efficient allocation in the economy under consideration we need a separate argument. For that, we first note that in an equal sacrifice allocation the utility levels different agents attain can never move in an opposite direction when the sacrifice level $s$ is changed. This is obvious since - according to equations (2) and (7) and the definition of $G^{M}(s)$ - the utility of each agent must change in the same direction as $G^{M}(s)-s$.

Now suppose that there are two different sacrifice levels $s^{*}$ and $s^{* *}$ for which $\Pi^{M}\left(s^{* *}\right)=\prod^{M}\left(s^{*}\right)=1$ holds such that two Pareto-optimal allocations would exist. It is a direct consequence of our observation concerning the parallel change of all agent's utilities that in this case $u_{i}\left(x_{i}^{M}\left(s^{*}\right), G^{M}\left(s^{*}\right)\right)=u_{i}\left(x_{i}^{M}\left(s^{* *}\right), G^{M}\left(s^{* *}\right)\right)$ for all $i=1, \ldots, n$, i.e. all agents have the same utility in both equal sacrifice solutions. Otherwise, a contradiction with the supposed Pareto optimality of the two equal sacrifice allocations would result.

Without loss of generality, $s^{* *}>s^{*}$ may be assumed so that, from strict monotonicity of the function $G^{M}(s)$, we get $G^{M}\left(s^{* *}\right)>G^{M}\left(s^{*}\right)$. Having the same utility levels in both allocations thus requires $x_{i}^{M}\left(s^{* *}\right)<x_{i}^{M}\left(s^{*}\right)$ for all agents $i=1, \ldots, n$. From the assumed normality of 
preferences we then get $\pi_{i}^{M}\left(s^{* *}\right)=\pi_{i}\left(x_{i}^{M}\left(s^{* *}\right), G^{M}\left(s^{* *}\right)\right)<\pi_{i}\left(x_{i}^{M}\left(s^{*}\right), G^{M}\left(s^{*}\right)\right)=\pi_{i}^{M}\left(s^{*}\right)$ for all agents $i=1, \ldots, n$. This gives $1=\prod^{M}\left(s^{* *}\right)=\sum_{i=1}^{n} \pi_{i}^{M}\left(s^{* *}\right)<\sum_{i=1}^{n} \pi_{i}^{M}\left(s^{*}\right)=\prod^{M}\left(s^{*}\right)=1$ which is a contradiction. So we can conclude:

Proposition 3: There is a unique sacrifice level $s^{*}$ such that the equal sacrifice allocation $\left(x_{1}^{M}\left(s^{*}\right), \ldots, x_{n}^{M}\left(s^{*}\right), G^{M}\left(s^{*}\right)\right)$ is Pareto optimal.

Using Proposition 3, the mechanism that picks an equal sacrifice solution is now characterized as follows:

Definition 3: Let a public goods economy be given by the income distribution $\left(y_{1}, \ldots, y_{n}\right)$ and preferences $\left(u_{1}, \ldots, u_{n}\right)$. Then the equal sacrifice solution for this public goods economy is defined as $\left(\hat{x}_{1}^{M}, \ldots, \hat{x}_{n}^{M}, \hat{G}^{M}\right)=\left(x_{1}^{M}\left(\hat{s}^{M}\right), \ldots, x_{n}^{M}\left(\hat{s}^{M}\right), G^{M}\left(\hat{s}^{M}\right)\right)$ where the sacrifice level $\hat{s}^{M}:=s^{*}$ is determined according to Proposition 3.

Given normality, the equal sacrifice solution as characterized by Definition 3 is well-defined and unique.

\section{Comparison with the Literature}

It is now straightforward that the equal sacrifice solution according to Definition 3 coincides with the egalitarian-equivalent allocation of the given economy (see Moulin, 1987, 1995). Given an income distribution $\left(y_{1}, \ldots, y_{n}\right)$ and preferences $\left(u_{1}, \ldots, u_{n}\right)$ define $\bar{G}^{M}:=\hat{G}^{M}-\hat{s}^{M}$. From condition (2) we then have

$$
u_{i}\left(\hat{x}_{i}^{M}, \hat{G}^{M}\right)=u_{i}\left(y_{i}, \bar{G}^{M}\right)
$$

so that $\bar{G}^{M}$ is the egalitarian-equivalent public-good supply in the sense of Moulin. Using a line of the argument different from that of Moulin, we have thus been able to link the egalitarian equivalent solution concept to the equal sacrifice principle. (For justifications of the Moulin solution see - besides Moulin, 1987, himself - Maniquet and Sprumont, 2004.) 
In this way, it becomes also possible to compare Moulin's approach with the much older Lindahl solution. To this end, we define - quite analogous to (2) - for any given feasible allocation $A=\left(\tilde{x}_{1}, \ldots, \tilde{x}_{n}, \tilde{G}\right)$, an alternative Lindahl-sacrifice by letting

$$
s_{i}^{L}(A):=\frac{\tilde{g}_{i}}{\pi_{i}\left(\tilde{x}_{i}, \tilde{G}\right)}
$$

where $\tilde{g}_{i}=y_{i}-\tilde{x}_{i}$ again denotes agent $i$ 's contribution to the public good in A.

The sacrifice level according to (14) is measured by using the marginal valuation of the private good in units of the public good in position $\left(\tilde{x}_{i}, \tilde{G}\right)$ instead of the total willingness to pay (see, e.g. Ebert, 2003, and Ebert and Tillmann, 2006, for a general discussion of the marginal valuation approach in a public goods economy). This Lindalian measurement device is visualized in Figure 3.

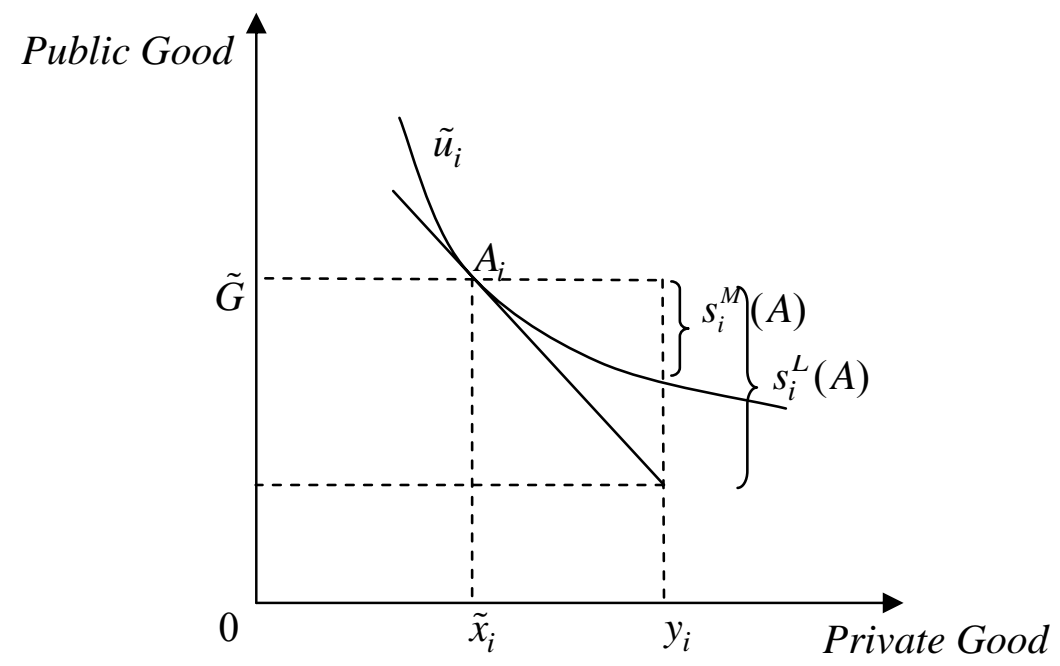

\section{Figure 3}

It is obvious from Figure 3 that with strictly convex indifference curves $s_{i}^{L}(A)>s_{i}^{M}(A)$ is automatically implied, i.e. the level of the Lindahl sacrifice always exceeds the level of the sacrifice expounded in this paper.

It again follows from normality that the Lindahl sacrifice has the same properties as stated in Proposition 1. We can also identify equal sacrifice allocations that are based on the Lindahlian sacrifice concept. The corresponding choice mechanism then picks an allocation $\left(\hat{x}_{1}^{L}, \ldots, \hat{x}_{n}^{L}, \hat{G}\right)$ that implies an equal Lindahl sacrifice for all agents and, as well, is efficient. It has been shown in Buchholz and Peters (2007) that the Lindahlian equal sacrifice allocation $\left(\hat{x}_{1}^{L}, \ldots, \hat{x}_{n}^{L}, \hat{G}^{L}\right)$ is identical with the standard Lindahl equilibrium that would be chosen if the 
agents $i=1, \ldots, n$ acted as price-takers and agent $i$ was confronted with the personalized Lindahl price $\hat{p}_{i}:=\pi_{i}\left(\hat{x}_{i}^{L}, \hat{G}^{L}\right)$. (For other distributional features of the Lindahl solution see Buchholz, Cornes and Peters, 2006.)

Even though the sacrifice measures $s_{i}^{M}$ and $s_{i}^{L}$ are conceptually different, they may yield the same efficient equal sacrifice solutions under specific circumstances. This is, e.g., the case if all agents have identical Cobb-Douglas preferences. Then, application of both equal sacrifice concepts implies that, in the corresponding equal sacrifice solutions, the public-good contributions of all agents $i=1, \ldots, n$ are proportional to their income levels $y_{i}$ (see the Appendix A2 for a detailed analysis of the Cobb-Douglas case).

\section{Properties of the Equal Sacrifice Solutions}

In this Section we show that the equal sacrifice solution as characterized in this paper satisfies both the ability-to-pay principle and the benefit principle. (Concerning the empirical relevance of the two principles in the case of global public goods, see Barrett, 2006, pp. 365-366.) To make this precise we first have to define exactly what these principles are to mean.

Concerning ability to pay, we assume that two agents $j$ and $k$ have the same utility function but differ with respect to their income, so that, without loss of generality, $y_{k}>y_{j}$ holds. If some arbitrary choice mechanism $E$ picks an allocation $\left(\hat{x}_{1}^{E}, \ldots, \hat{x}_{n}^{E}, \hat{G}^{E}\right)$ with individual public-good contributions $\hat{g}_{i}^{E}:=y_{i}-\hat{x}_{i}^{E}$, this mechanism is said to satisfy the (weak) ability to pay principle if $\hat{g}_{k}^{E} \geq \hat{g}_{j}^{E}$ holds, i.e. if the richer agent $k$ does not make a smaller contribution to the public good than the poorer agent $j$ does.

Analogously, the (weak) benefit principle requires that, given the same income level, an agent with a stronger preference for the public good, as defined by reference to marginal willingness to pay in condition (6), should not make a smaller contribution to the public good than an agent with a weaker preference (see Hines, 2000, for a general discussion of the benefit principle). If this condition is met and if, additionally, $y_{j}=y_{k}$ holds, the benefit principle is satisfied for a mechanism $E$ if and only if $\hat{g}_{k}^{E} \geq \hat{g}_{j}^{E}$. (For a general discussion of the benefit principle see Hines, 2000.)

It is now a straightforward consequence of Proposition 1 that both principles are satisfied for equal sacrifice solutions. Assume that the public-good contribution of agent $k$ would be smaller than that of agent $j$ if the income of agent $k$ were higher than that of agent $j$, or 
agent $k$ 's preferences for the public good were stronger than that of agent $j$. Combining the results of Proposition 1 (i) with those in Proposition 1 (iii) or (iv), respectively, this implies that agent $k$ would have to bear a smaller sacrifice than agent $j$ which contradicts the equal sacrifice assumption.

\section{Conclusion}

This paper has shown how, in a standard public goods economy, the venerable equal sacrifice principle can be applied to make a selection among efficient allocations. Unlike the traditional literature, however, we did not make use of losses in cardinally measurable utility as an indicator of individual sacrifice. Instead we obtained a sacrifice measure by transforming the individual expenses for the public good into public-good equivalents. The method by which this transformation was made was borrowed from the willingness-to-pay assessment well known from the contingent valuation techniques used in environmental economics. The public-good allocations, that show an equal sacrifice defined in this way and are also Pareto optimal, turn out to be identical with the egalitarian equivalent solutions as conceived by Moulin (1987). Moreover, they satisfy the ability-to-pay and the benefit principles properly defined.

The novel justification of the egalitarian equivalent solution concept provided in this paper also makes it possible to recognize its similarity with the classical Lindahl equilibrium, since the Lindahl mechanism can also be put down to the equal sacrifice principle. The difference, however, is that assessment of the sacrifice as made in our approach is based on total willingness-to-pay or, in an alternative interpretation, average valuation of the public good, whereas the Lindahl solution rests upon the valuation of the public-goods contribution according to marginal willingness-to-pay. In special cases both equal sacrifice solutions may coincide but generally they will be different.

Measuring individual sacrifice by total valuations as in the present paper, takes into account more information about individual preferences than the Lindahl approach in which assessment of sacrifice is only based on marginal willingness-to-pay at a single point. In a world of full information, as assumed here (and also in the standard treatments of the Lindahl and the egalitarian equivalent solution concepts), the solution described in this paper is therefore based on a more accurate valuation of individual sacrifice than is its Lindahl counterpart. 


\section{Appendix A1: Steepness of Indifference Curves}

Consider agent $i$ and fix some level $x_{i}$ of her private consumption. Let, as in the main text, $\vec{u}_{i}^{\prime}$ and $\vec{u}_{i}^{\prime \prime}$ be two utility levels of agent $i$ with $\vec{u}_{i}^{\prime \prime}>\vec{u}_{i}^{\prime}$. By $G^{\prime}$ and $G^{\prime \prime}$ we then denote the levels of public-good supply for which $u_{i}\left(x_{i}, G^{\prime}\right)=\vec{u}_{i}^{\prime}$ and $\vec{u}_{i}^{\prime}\left(x_{i}, G^{\prime \prime}\right)=\vec{u}_{i}^{\prime \prime}$ holds. Now assume $p_{i}^{\prime \prime}:=\varphi_{i}^{h}\left(x_{i}, \bar{u}_{i}^{\prime \prime}\right)<\varphi_{i}^{h}\left(x_{i}, \bar{u}_{i}^{\prime}\right)=: p_{i}^{\prime}$, i.e. that the indifference curve $\bar{u}_{i}^{\prime \prime}$ at $\left(x_{i}, G^{\prime \prime}\right)$ is flatter than the indifference curve $\vec{u}_{i}^{\prime}$ at $\left(x_{i}, G^{\prime}\right)$. Thus, as depicted in Figure 5, agent $i$ endowed with the income $y_{i}^{\prime \prime}:=x_{i}+p_{i}^{\prime} G^{\prime \prime}$ and confronted with the public-good price $p_{i}^{\prime}$ would demand less of the private good than $x_{i}$.

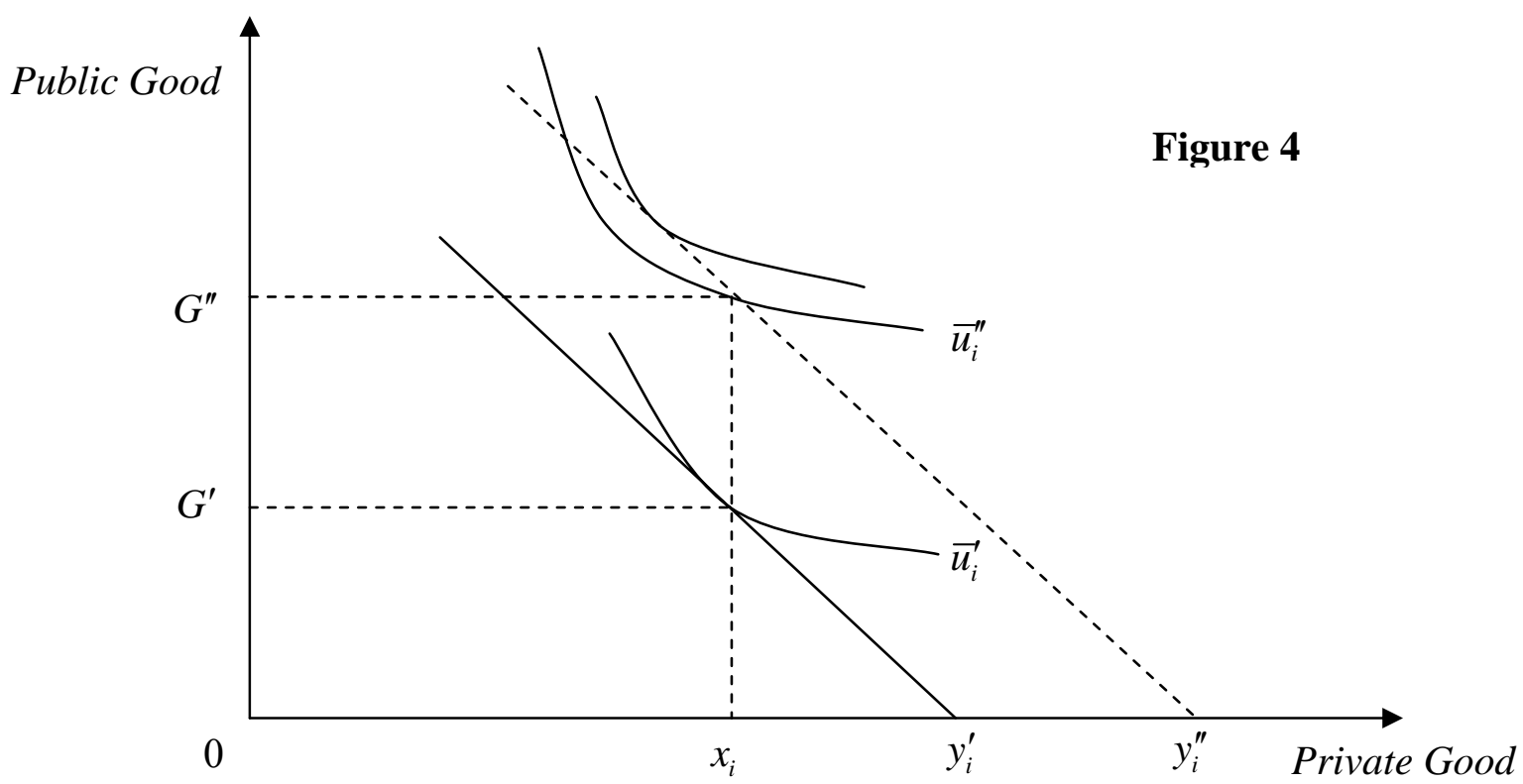

Since $x_{i}$ is agent $i$ 's private good demand, given the income $y_{i}^{\prime}=x_{i}+p_{i}^{\prime} G^{\prime}$ and the public good price $p_{i}^{\prime}$, and clearly $y_{i}^{\prime}<y_{i}^{\prime \prime}$ holds, this would contradict the assumption that the private good is normal.

Since indifference curves are convex it is a straightforward implication of this argument that indifference curves become steeper if public good consumption grows and private good consumption falls simultaneously.

\section{A2: The Equal Sacrifice Solution in the Cobb-Douglas Case}

Let $n$ agents $i=1, \ldots, n$ be given by their income levels $y_{1}, \ldots, y_{n}$ and their Cobb-Douglas utility functions $u_{i}\left(x_{i}, G\right)=x_{i} G^{\rho_{i}}$. In the equal sacrifice solution $\left(\hat{x}_{1}^{M}, \ldots, \hat{x}_{n}^{M}, \hat{G}^{M}\right)$ the common equal sacrifice level $\hat{s}^{M}$ must satisfy $\hat{x}_{i}^{M}\left(\hat{G}^{M}\right)^{\rho_{i}}=y_{i}\left(\hat{G}^{M}-\hat{s}^{M}\right)^{\rho_{i}}$ for all agents $i=1, \ldots, n$ 
which yields $\hat{s}^{M}=\hat{G}^{M}\left(1-\left(\frac{\hat{x}_{i}^{M}}{y_{i}}\right)^{\frac{1}{\rho_{i}}}\right)$ for the common sacrifice level. For individual private consumption, we obtain $\hat{x}_{i}^{M}=A^{\rho_{i}} y_{i}$, where $A:=\frac{\hat{G}^{M}-\hat{s}^{M}}{\hat{G}^{M}}<1$ is a constant for the given publicgoods economy. The individual public-good contributions then are $\hat{g}_{i}^{M}=\left(1-A^{\rho_{i}}\right) y_{i}$.

This expression clearly confirms the results of Proposition 4 in the main text for the Cobb-Douglas case. If two agents $j$ and $k$ have the same preferences, i.e. $\rho_{j}=\rho_{k}$ holds, but $y_{k}>y_{j}$, then $\hat{g}_{k}^{M}>\hat{g}_{j}^{M}$ so that the agent with the higher income makes a higher contribution to the public good and ability to pay is fulfilled. If, on the other hand, two agents $j$ and $k$ have the same income $y_{j}=y_{k}$ but $\rho_{k}>\rho_{j}$, we have again $\hat{g}_{k}^{M}>\hat{g}_{j}^{M}$, i.e. the agent with the stronger preference for the public good makes a higher contribution, which gives the benefit principle.

We now compare our equal sacrifice solution with the Lindahl equilibrium $\left(\hat{x}_{1}^{L}, \ldots, \hat{x}_{n}^{L}, \hat{G}^{L}\right)$ that results in the same situation. Here, individual public good contributions are $\hat{g}_{i}^{L}=\frac{\rho_{i}}{1+\rho_{i}} y_{i}$ for agents $i=1, \ldots, n$. When all agents have the same preferences, so that $\rho=\rho_{i}$ for $i=1, \ldots, n$, it directly follows from our formulas that public-good contributions must be proportional to the individual income level in both solutions. Since efficiency of both outcurves requires $\hat{G}^{M}=\hat{G}^{L}=\frac{\rho}{1+\rho} Y$ where $Y=\sum_{i=1}^{n} y_{i}$ is total income, both equal sacrifice solutions coincide when all agents have the same Cobb-Douglas preferences.

However, when agents have different Cobb-Douglas preferences, the equal sacrifice solution $\left(\hat{x}_{1}^{M}, \ldots, \hat{x}_{n}^{M}, \hat{G}^{M}\right)$ may differ from $\left(\hat{x}_{1}^{L}, \ldots, \hat{x}_{n}^{L}, \hat{G}^{L}\right)$. This is demonstrated by the following simple example: Let $n=2, y_{1}=y_{2}=1$ and $\rho_{1}=1$ and $\rho_{2}=2$. Then clearly $\hat{x}_{1}^{L}=\frac{1}{2}$, $\hat{x}_{2}^{L}=\frac{1}{3}, \hat{g}_{1}^{L}=\frac{1}{2}, \hat{g}_{2}^{L}=\frac{1}{3}$ and $\hat{G}^{L}=\frac{7}{6}=1,17$. The utility levels of the two agents are $\hat{u}_{1}^{L}=0.58$ and $\hat{u}_{1}^{L}=0.45$. On the other hand, $\hat{x}_{2}^{M}=\left(\hat{x}_{1}^{M}\right)^{2}$ which - combined with the feasibility condition and the Samuelson rule for efficiency - leads to the quadratic equation $3\left(x_{1}^{M}\right)^{2}+2 \hat{x}_{1}^{M}-2=0$. Solving this equation for $\hat{x}_{1}^{M}$ yields $\hat{x}_{1}^{M}=0.55$, which then implies $\hat{x}_{2}^{M}=0.3, \hat{g}_{1}^{M}=0.45, \hat{g}_{2}^{M}=0.7$ and thus $\hat{G}^{M}=1.15$. This shows that both solutions need not 
be identical. For the utility levels we obtain $\hat{u}_{1}^{M}=0.63$ and $\hat{u}_{2}^{M}=0.4$ so that agent 1 with the lower preference for the public good is worse off in the Lindahl solution where for agent 2 the reverse result holds.

In the general case with non-homogenous Cobb-Douglas preferences an explicit comparison between the two solutions is difficult to make since no closed form expression for the Moulin outcome exists in this case. 


\section{References}

Barrett, S. (2006), Making International Cooperation Pay - Financing as a Strategic Incentive, in: I. Kaul and P. Conceição, eds., The New Public Finance, Oxford University Press, Oxford, UK, 357-356.

Bergstrom, T. (2006), Benefit-Cost in a Benevolent Society, American Economic Review 96, 339-351.

Bergstrom, T., Blume, L. and H. Varian (1986), On the Private Provision of Public Goods, Journal of Public Economics 29, 25-49.

Buchholz, W. and W. Peters (2007), Justifying the Lindahl Solution as the Outcome of Fair Cooperation, forthcoming in: Public Choice.

Buchholz, W., Cornes, R. and W. Peters (2006), Lindahl Equilibrium Versus Voluntary Contribution to the Public Good: The Role of the Income Distribution, FinanzArchiv/Public Finance Analysis 62, 28-49.

Cornes, R. and T. Sandler (1996), The Theory of Externalities, Public Goods and Club Goods, $2^{\text {nd }}$ ed., Cambridge University Press, Cambridge, UK.

Ebert, U. (1993), A Note on the Willingness to Pay and the Willingness to Accept, Social Choice and Welfare 10, 363-370.

Ebert, U. (2003), Environmental Goods and the Distribution of Income, Environmental and Resource Economics 25, 435-459.

Ebert, U. and G. Tillmann (2006), Distribution Neutral Provision of Public Goods, forthcoming in: Social Choice and Welfare.

Hines, J. R. Jr. (2000), What is Benefit Taxation?, Journal of Public Economics 75, 483-492. 
Kaul, I. and P. Conceição, eds., (2006), The New Public Finance, Oxford University Press, Oxford, UK.

Kaul, I., Grunberg, I. and M. A. Stern, eds. (1999), Global Public Goods: Cooperation for the $21^{\text {st }}$ Century, Oxford University Press, Oxford, UK.

Kaul, I. et al., eds. (2003), Providing Global Public Goods : Managing Globalization, Oxford University Press, Oxford, UK.

Kolstad, Ch. (2000), Environmental Economics, Oxford University Press, Oxford UK.

Lange, A., Vogt, C. and A. Ziegler (2007), On the Importance of Equity in International Climate Policy: An Empirical Analysis, Energy Economics 29, 545-562.

Maniquet, F. and Y. Sprumont (2004), Fair Production and Allocation of an Excludable Nonrival Good, Econometrica 72, 627-640.

Mitra, T. and E. A. Ok (1996), Personal Income Taxation and the Principle of Equal Sacrifice Revisited, International Economic Review 37, 925-948.

Moulin, H. (1987), Egalitarian Equivalent Cost Sharing of a Public Good, Econometrica 55, 963-976.

Moulin, H. (1995), Cooperative Microeconomics, Princeton University Press, Princeton, NJ.

Moyes, P. (2003), Redistributive Effects of Minimal Equal Sacrifice Taxation, Journal of Economic Theory 108, 113-140.

Musgrave, R. A. (1959), The Theory of Public Finance, McGraw Hill, New York.

Nordhaus, W. D. (2005), Paul Samuelson and Global Public Goods, Discussion Paper, Yale University. 
Neill, J. F. (2000), The Benefit and the Sacrifice Principles of Taxation: A Synthesis, Social Choice and Welfare 17, 117-124.

Sandler, T. (1992), Collective Action: Theory and Applications, University of Michigan Press, Ann Arbor.

Sandler, T. (2004), Global Collective Action, Cambridge University Press, Cambridge, UK.

Sandmo, A. (2006), Global Public Economics: Public Goods and Externalities, Discussion Paper, Norwegian School of Economics and Business Administration, Bergen.

Schlesinger, H. and D. Sullivan (1986), Canons of Just Taxation: Efficiency and Fairness in an Economy with a Public Good, Public Finance Quarterly 14, 448-465.

Stern, N. (2006), The Stern Review of the Economics of Climate Change, HM Treasury, London, UK. 


\section{CESifo Working Paper Series}

(for full list see www.cesifo-group.de)

1932 Wilhelm Kohler, The Bazaar Effect, Unbundling of Comparative Advantage, and Migration, February 2007

1933 Karsten Staehr, Fiscal Policies and Business Cycles in an Enlarged Euro Area, February 2007

1934 Michele Bernasconi and Paola Profeta, Redistribution or Education? The Political Economy of the Social Race, March 2007

1935 Axel Dreher, Martin Gassebner and Lars-H. R. Siemers, Does Terror Threaten Human Rights? Evidence from Panel Data, March 2007

1936 Naércio Aquino Menezes Filho and Marc-Andreas Muendler, Labor Reallocation in Response to Trade Reform, March 2007

1937 Gebhard Flaig and Timo Wollmershaeuser, Does the Euro-zone Diverge? A Stress Indicator for Analyzing Trends and Cycles in Real GDP and Inflation, March 2007

1938 Michael Funke and Michael Paetz, Environmental Policy Under Model Uncertainty: A Robust Optimal Control Approach, March 2007

1939 Byeongchan Seong, Sung K. Ahn and Peter A. Zadrozny, Cointegration Analysis with Mixed-Frequency Data, March 2007

1940 Monika Bütler and Michel André Maréchal, Framing Effects in Political Decision Making: Evidence from a Natural Voting Experiment, March 2007

1941 Giacomo Corneo and Olivier Jeanne, A Theory of Tolerance, March 2007

1942 Qing Hong and Michael Smart, In Praise of Tax Havens: International Tax Planning and Foreign Direct Investment, March 2007

1943 Yin-Wong Cheung, Dickson Tam and Matthew S. Yiu, Does the Chinese Interest Rate Follow the US Interest Rate?, March 2007

1944 Panu Poutvaara and Mikael Priks, Unemployment and Gang Crime: Could Prosperity Backfire?, March 2007

1945 Burkhard Heer, On the Modeling of the Income Distribution Business Cycle Dynamics, March 2007

1946 Christoph A. Schaltegger and Lars P. Feld, Are Fiscal Adjustments less Successful in Decentralized Governments?, March 2007 
1947 Giovanni Facchini, Marcelo Olarreaga, Peri Silva and Gerald Willmann, Substitutability and Protectionism: Latin America's Trade Policy and Imports from China and India, March 2007

1948 C. Mirjam van Praag and Bernard M. S. van Praag, The Benefits of Being Economics Professor A (and not Z), March 2007

1949 Astrid Hopfensitz and Frans van Winden, Dynamic Choice, Independence and Emotions, March 2007

1950 Guglielmo Maria Caporale and Luis A. Gil-Alana, A Multivariate Long-Memory Model with Structural Breaks, March 2007

1951 Mattias Ganslandt and Keith E. Maskus, Wholesale Price Discrimination and Parallel Imports, March 2007

1952 Michela Redoano, Fiscal Interactions Among European Countries. Does the EU Matter?, March 2007

1953 Stefan C. Wolter, Rémy Hübschi and Matthias Müller, Push or Pull? An Empirical Analysis of the Demand for Individual Project Grants from the Swiss National Science Foundation, March 2007

1954 Scott Alan Carson, African-American and White Inequality in the American South: Evidence from the $19^{\text {th }}$ Century Missouri State Prison, March 2007

1955 Peter Egger, Marko Koethenbuerger and Michael Smart, Do Fiscal Transfers Alleviate Business Tax Competition? Evidence from Germany, March 2007

1956 Panu Poutvaara and Lars-H. R. Siemers, Smoking and Social Interaction, March 2007

1957 Stephan Danninger and Fred Joutz, What Explains Germany's Rebounding Export Market Share?, March 2007

1958 Stefan Krasa and Mattias Polborn, Majority-efficiency and Competition-efficiency in a Binary Policy Model, March 2007

1959 Thiess Buettner and Georg Wamser, Intercompany Loans and Profit Shifting Evidence from Company-Level Data, March 2007

1960 Per Pettersson-Lidbom and Mikael Priks, Behavior under Social Pressure: Empty Italian Stadiums and Referee Bias, April 2007

1961 Balázs Égert and Carol S. Leonard, Dutch Disease Scare in Kazakhstan: Is it real?, April 2007

1962 Paul De Grauwe and Pablo Rovira Kaltwasser, Modeling Optimism and Pessimism in the Foreign Exchange Market, April 2007 
1963 Volker Grossmann and Thomas M. Steger, Anti-Competitive Conduct, In-House R\&D, and Growth, April 2007

1964 Steven Brakman and Charles van Marrewijk, It's a Big World After All, April 2007

1965 Mauro Ghinamo, Paolo M. Panteghini and Federico Revelli, FDI Determination and Corporate Tax Competition in a Volatile World, April 2007

1966 Inés Macho-Stadler and David Pérez-Castrillo, Optimal Monitoring to Implement Clean Technologies when Pollution is Random, April 2007

1967 Thomas Eichner and Ruediger Pethig, Efficient $\mathrm{CO}_{2}$ Emissions Control with National Emissions Taxes and International Emissions Trading, April 2007

1968 Michela Redoano, Does Centralization Affect the Number and Size of Lobbies?, April 2007

1969 Christian Gollier, Intergenerational Risk-Sharing and Risk-Taking of a Pension Fund, April 2007

1970 Swapan K. Bhattacharya and Biswa N. Bhattacharyay, Gains and Losses of India-China Trade Cooperation - a Gravity Model Impact Analysis, April 2007

1971 Gerhard Illing, Financial Stability and Monetary Policy - A Framework, April 2007

1972 Rainald Borck and Matthias Wrede, Commuting Subsidies with two Transport Modes, April 2007

1973 Frederick van der Ploeg, Prudent Budgetary Policy: Political Economy of Precautionary Taxation, April 2007

1974 Ben J. Heijdra and Ward E. Romp, Retirement, Pensions, and Ageing, April 2007

1975 Scott Alan Carson, Health during Industrialization: Evidence from the $19^{\text {th }}$ Century Pennsylvania State Prison System, April 2007

1976 Andreas Haufler and Ian Wooton, Competition for Firms in an Oligopolistic Industry: Do Firms or Countries Have to Pay?, April 2007

1977 Eckhard Janeba, Exports, Unemployment and the Welfare State, April 2007

1978 Gernot Doppelhofer and Melvyn Weeks, Jointness of Growth Determinants, April 2007

1979 Edith Sand and Assaf Razin, The Role of Immigration in Sustaining the Social Security System: A Political Economy Approach, April 2007

1980 Marco Pagano and Giovanni Immordino, Optimal Regulation of Auditing, May 2007

1981 Ludger Woessmann, Fundamental Determinants of School Efficiency and Equity: German States as a Microcosm for OECD Countries, May 2007 
1982 Bas Jacobs, Real Options and Human Capital Investment, May 2007

1983 Steinar Holden and Fredrik Wulfsberg, Are Real Wages Rigid Downwards?, May 2007

1984 Cheng Hsiao, M. Hashem Pesaran and Andreas Pick, Diagnostic Tests of Cross Section Independence for Nonlinear Panel Data Models, May 2007

1985 Luis Otávio Façanha and Marcelo Resende, Hierarchical Structure in Brazilian Industrial Firms: An Econometric Study, May 2007

1986 Ondřej Schneider, The EU Budget Dispute - A Blessing in Disguise?, May2007

1987 Sascha O. Becker and Ludger Woessmann, Was Weber Wrong? A Human Capital Theory of Protestant Economic History, May 2007

1988 Erkki Koskela and Rune Stenbacka, Equilibrium Unemployment with Outsourcing and Wage Solidarity under Labour Market Imperfections, May 2007

1989 Guglielmo Maria Caporale, Juncal Cunado and Luis A. Gil-Alana, Deterministic versus Stochastic Seasonal Fractional Integration and Structural Breaks, May 2007

1990 Cláudia Costa Storti and Paul De Grauwe, Globalization and the Price Decline of Illicit Drugs, May 2007

1991 Thomas Eichner and Ruediger Pethig, Pricing the Ecosystem and Taxing Ecosystem Services: A General Equilibrium Approach, May 2007

1992 Wladimir Raymond, Pierre Mohnen, Franz Palm and Sybrand Schim van der Loeff, The Behavior of the Maximum Likelihood Estimator of Dynamic Panel Data Sample Selection Models, May 2007

1993 Fahad Khalil, Jacques Lawarrée and Sungho Yun, Bribery vs. Extortion: Allowing the Lesser of two Evils, May 2007

1994 Thorvaldur Gylfason, The International Economics of Natural Resources and Growth, May 2007

1995 Catherine Roux and Thomas von Ungern-Sternberg, Leniency Programs in a Multimarket Setting: Amnesty Plus and Penalty Plus, May 2007

1996 J. Atsu Amegashie, Bazoumana Ouattara and Eric Strobl, Moral Hazard and the Composition of Transfers: Theory with an Application to Foreign Aid, May 2007

1997 Wolfgang Buchholz and Wolfgang Peters, Equal Sacrifice and Fair Burden Sharing in a Public Goods Economy, May 2007 